See discussions, stats, and author profiles for this publication at: https://www.researchgate.net/publication/342715084

\title{
Stakeholder Tensions in Decision-Making for Opening Government Data
}

Chapter · July 2020

DOI: 10.1007/978-3-030-52306-0_23

CITATIONS

0

3 authors:

Ahmad Luthfi

U. Universitas Islam Indonesia

30 PUBLICATIONS 119 CITATIONS

SEE PROFILE

A. Joep Crompvoets

ge KU Leuven

203 PUBLICATIONS 1,351 CITATIONS

SEE PROFILE

Some of the authors of this publication are also working on these related projects:

SPATIALIST View project

AW4city 2017, 3rd International ACM Smart City Workshop: Enhancing Livability with Web Applications for smart cities View project
READS

158

Marijn Janssen

Delft University of Technology

596 PUBlications 11,580 Citations

SEE PROFILE 


\title{
Stakeholder Tensions in Decision-Making for Opening Government Data
}

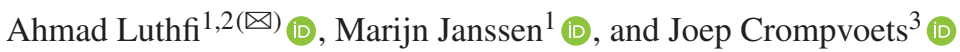 \\ ${ }^{1}$ Faculty of Technology, Policy and Management, Delft University of Technology, Jaffalaan 5, \\ 2628 BX Delft, The Netherlands \\ \{a.luthfi,m.f.w.h.a.janssen\}@tudelft.nl \\ 2 Universitas Islam Indonesia, Yogyakarta, Indonesia \\ ahmad.luthfi@uii.ac.id \\ 3 Katholieke Universiteit Leuven, Leuven, Belgium \\ joep.crompvoets@kuleuven. be
}

\begin{abstract}
Various types of stakeholders are often involved in the process of deciding to open data. However, the influence of multiple-actors on the decision-making process is ill-understood. Stakeholders play different roles and have different interests in opening and analyzing datasets. The objective of this paper is to understand the influence of the stakeholder's roles and their interests in the decision-making process to open data. The roles-interest grid method is used to determine the stakeholder's concerns and how they influence the decision-making process to open data. In addition to stakeholder theory, we employ muddling through and bounded rationality theories to create a comprehensive analysis of the decisionmaking process. Stakeholders are found to be diverse, where some are proponents of opening data, and others are risk-averse and do not favor disclosing data. Stakeholder's responsible for the actual opening of data are often focused on the risks resulting in a tension between the ambitions of politicians to open data, and the practices of administrators and decision-makers. Understanding the stakeholder's roles and their tensions can help to ensure better decisions are made. We recommend creating incentives for generating shared objectives.
\end{abstract}

Keywords: Stakeholder · Open government data $\cdot$ Decision-making $\cdot$ Roles · Interest $\cdot$ Muddling through $\cdot$ Bounded rationality

\section{Introduction}

Making decision process to either open or closed the dataset by the government institutions is not trivial and faces many complexities. The main challenge encountered is the involvement of stakeholders having various interests and concerns in the decisionmaking process, like politicians, executive boards, decision-makers, civil servants, and administrative officers, all with their distinct perspectives and agendas [1]. These stakeholders play all different roles in the decision-making process of opening data ranging from setting the objectives and ambitions to the actual opening of data.

(C) Springer Nature Switzerland AG 2020

B. Shishkov (Ed.): BMSD 2020, LNBIP 391, pp. 331-340, 2020.

https://doi.org/10.1007/978-3-030-52306-0_23 
The diversity of actors and their interests, various interpretations of strict regulations, limited knowledge and expertise, lack of personal skills, and barriers of technology acceptance at the management level are all influencing the decision-making process of opening data $[2,3]$. As a result, the decision-making process becomes fuzzy, and the objectives of opening data are not realized. Besides, the different roles and interests of the heterogonous actors in the internal government organization might create an erratic and slow decision-making process.

For example, some decision-makers might have high authority to publish or keep closed the dataset. Furthermore, some public servants might be risks-adverse, whereas others might just open datasets without thinking about the possible negative consequences. In general, perceptions on the pros and cons of open data can be different among stakeholders. The dominating view on deciding to open data is that of being a systematic and structured process in which a careful trade-off is taken between the pros and cons of opening data, and then the best decision is made. However, reality might be more cumbersome due to the complex relationships and different roles and interests of stakeholders.

The objective of this paper is to analyze the stakeholder's roles and their interests in the decision-making process to open data. This should result in the identification of tensions between stakeholder's roles and their interest. The role versus interest grid method is to analyze stakeholder positions and can help to effectively engage and support all the stakeholders in the decision-making process $[4,5]$. This method can determine the concern stakeholders have and how they influence the decision-making process in opening data.

In order to make a comprehensive analysis, we employed two theories, namely muddling through and bounded rationality. The first theory is used to analyze complex problems in the decision-making process to open data by considering the obstacles that stand between the initial problem state and the goal state. Bounded rationality is used to analyze decisions when rationality is limited. When the executives make decisions, they will trace the decision problems by taking account of their cognitive limitations, available resources, and time restriction.

\section{Related Work}

There are different types of stakeholders. Some of them have a higher degree in the organizational hierarchy and can decide the course of action [6]. Some decision-makers can approve or veto decisions on a decision-making process [7]. Another set of stakeholders can aid with their expert opinion and knowledge [8]. Moreover, several stakeholders help oversee the project from the beginning, during implementing and making the decisions [6]. Hence, stakeholders should understand how the project scope, goals, and performance indicators.

In the domain of Open Government Data (OGD), the backgrounds of multiple actors in the decision-making process are often heterogeneous. Some stakeholders set the policy, others might want to know the progress of the current decision-making process, the time to make a decision, and the outcome of the decisions. However, not all stakeholders are equally involved in the decision-making process from the beginning. Some 
are positioned to take responsibility to direct or provide input for others to make a decision. Therefore, in this study, stakeholder analysis contributes to analyze the stakeholder positions and how to engage these different types of stakeholders.

\subsection{The Science of Muddling Through}

In the science of muddling through, the decision-making process is looked at as a complex process with many vague small steps [9]. Decision-makers have to cross through the mud (muddling through) and big steps are not possible [9,10]. As a result, changing policy is in most cases an evolutionary process instead of a revolutionary process [9]. For example, Lindblom, who was the originator of the theory of muddling through, wondered why the government used rational methods with their absolute belief when people are rationally limited [11].

Lindblom introduced two ideal types of policy-making method, namely the root and branch method. First, the "root" method or rational comprehension method refers to the view in which decisions are made at the bottom level of the root [11]. The problem is decomposed down completely rationally [9]. However, this method did not suitable in some cases, because people are limited rational to solve decision-making problems or these are usually too complicated $[9,11]$. Second, "branch" method or also known as successful limited comparison method where this always small steps in decisions [11]. Afterward, narrow down the steps to find at what happens and make decisions iteration $[9,12]$.

Furthermore, the root method believes that it is possible to reach an agreement on organizational goals [10]. These goals can then be used to allocate resources, including human, technology and systems, and procedures $[9,11]$. The "branch" method, on the other hand, assumes that it is almost impossible to set clear goals due to the overly interests of stakeholder's involvement [11]. The resources used are usually also only available at that time and not necessarily require the best ones [11, 12]. The environment analysis of the root method is therefore much broader than that of the branch method [9]. The first method depends heavily on theory, but the second one does not need this because there is the frequent use of comparisons and the adjustment of goals $[9,10]$.

To sum up, with the root method, good policy is to achieve the objectives with the available resources. According to Lindblom, decision-makers and other policy-making stakeholders should implement the root method, but take into consideration the practice cases using the branch method $[9,10]$. Therefore, in this study, the muddling through theory contributes to a better understanding of the decision-making process to open data. This suggests that the opening of data is a less relational process and might be dependent on the persons who are involved. A study [13] found that the different organization makes different decisions about a similar type of data. This results in some datasets being opened by certain agencies, whereas other agencies do not open these types of datasets. This arbitrariness originates from differences in the decision-making process.

\subsection{Bounded Rationality}

The bounded rationality theory was introduced by Simon in 1957. Simon described that decision alternative is not given per situation, but it should be found, one after 
the other alternatives [14]. The bounded rationality is an approach to process decisionmaking when decision-makers have limited rationality [15]. Simon proposed the theory of bounded rationality as an alternative to substitute the fact that rationality decisions are often difficult to adapt in practice due to the intractability of natural decision-making problems [14].

Full rationality by stakeholders in the decision-making process may require unlimited cognitive capabilities [14]. In an organization, having a person who has capabilities in many fields like mathematics, computations, statistics, and decision-making expertise can be an ideal situation. However, in reality, human beings' cognitive competences are limited. For this reason, the decision-making behavior of stakeholders cannot accommodate the optimal decisions [14, 15].

To summarize, the theory of bounded rationality proposes that decision-makers have bounded rationality when faced with organizational decision-making problems. In this study, there are three main reasons the use of bounded rationality theory in the stakeholder's analysis domain. First, cognitive limitations can lead to different perception gaps among stakeholders in open data. Second, incomplete information and a lack of resources the stakeholders can create a wrong interpretation of the decision alternatives. Third, a lack of time to process decisions can affect decision-making delays. Besides, recognizing the diversity of stakeholders and their perspectives and interests is essential to understand the decision-making process to open data. Therefore, the bounded rationality contributes to a strategy when the rationality thinking of the stakeholders to process the decision-making is limited.

\section{Analyzing Stakeholders Using a Role-Interest Grid}

In this paper, we use electronic procurement (e-procurement) case study in Indonesia to capture the context of the decision-making process to OGD. We employ experimental case study to the stakeholders, which consist of 43 participants in total derived from several different organizations like governments, universities or academia, and professionals, or communities. The objective of this experimental case study is to identify the roles and interests of the stakeholders in the decision-making process to open or to analyze the government's datasets. There are two main steps to develop a role-interest grid of the decision-making process in the open data domain. First, we identify and construct a role-interest of different stakeholders to show the position and level of each stakeholder in terms of four quadrants. Second, we analyze the decision-making process.

\subsection{Identify and Construct a Role-Interest of the Different Stakeholders}

In this research, we define several main stakeholders who are involved as primary and secondary stakeholders. The primary stakeholders are derived from internal government entities, including the politicians, executive boards, policy-makers, decision-makers, civil servants, and administrative officers [16]. The secondary stakeholders are acquired from non-governmental ecosystems, including data enthusiasts, researchers, journalists, business enablers, and civil societies [2, 16, 17]. 
Moreover, the primary stakeholders refer to the actor of data publishers who have formal, official, hierarchical, and contractual relationships. These actors have a direct and degree of roles in the decision-making process. In addition, the secondary stakeholders represent the multiple actors of open data users. They are influenced by the open government datasets but less formal and do not directly contribute to the decision-making process of opening data.

The objective of the construction step is to show the group and prioritize these stakeholders. Here, we categorize the stakeholders in terms of their roles or influence, interests or impact, and levels of participation in the decision-making process to open data. The roles and interests of stakeholders' analysis presented in Fig. 1 reveal the following tensions:

1. The policy-makers and decision-makers have a strong influence and high interest in the decision-making process. The policy-makers set the policy-making agendas and translate the ideas into the execution of the policies. Decision-makers are responsible for providing decision alternatives and high interest to reuse the datasets to make better decisions at the same time. The decision-makers should follow the policies set by the government. Nevertheless, the policies are often not clear for a given dataset. Policy-makers and decision-makers may have a sufficiency of knowledge and resources to make decision alternatives.

2. The politicians and executive boards have a high role and less interest. The politicians can control both content and presence the open data legislation in the legislative level. Yet, most of the politicians are not interested in using the datasets for their individual benefits because of the cognitive limitation in analyzing the datasets. Executive boards, they can contribute to the decision-making process to open data. However, executive boards have a very limited time to re-analysis the datasets because of the organizational agendas.

3. The civil servants and administrative officers have a moderate role and moderate interest level in the decision-making process. The civil servants can play a role regularly to manage the coordination between internal stakeholders. Concurrently, the civil servants are moderately interested in re-analyze the impact of released datasets. Administrative officers maintain the open data portal and provide visual information to the public. At the same time, the administrative officers are moderately fascinated to re-analyze the dataset to know the impacts of opening datasets. Resources are scarce and the opening of data often comes as an afterthought. Data enthusiasts and business enablers have a moderate role and high interest in the decision-making process. These stakeholders require analyzing the datasets to an individual or organizational benefits. The business enablers can use the datasets for in-depth analysis to generate the customers' demand for a product. Their ambitions are often in tension with the civil servants that are more conservatives and risk-averse.

4. The researchers, journalists, and civil societies can all high interest in using datasets, but they are hardly engaged in the decision-making process. Being the external entities of government institutions, it makes these stakeholders difficult to involve in the decision-making process to open data. Even though researchers have sufficient knowledge and decision rationalities, the role gap between the internal and external stakeholders may become challenging. They might not be even aware of certain datasets, as these are not published. 


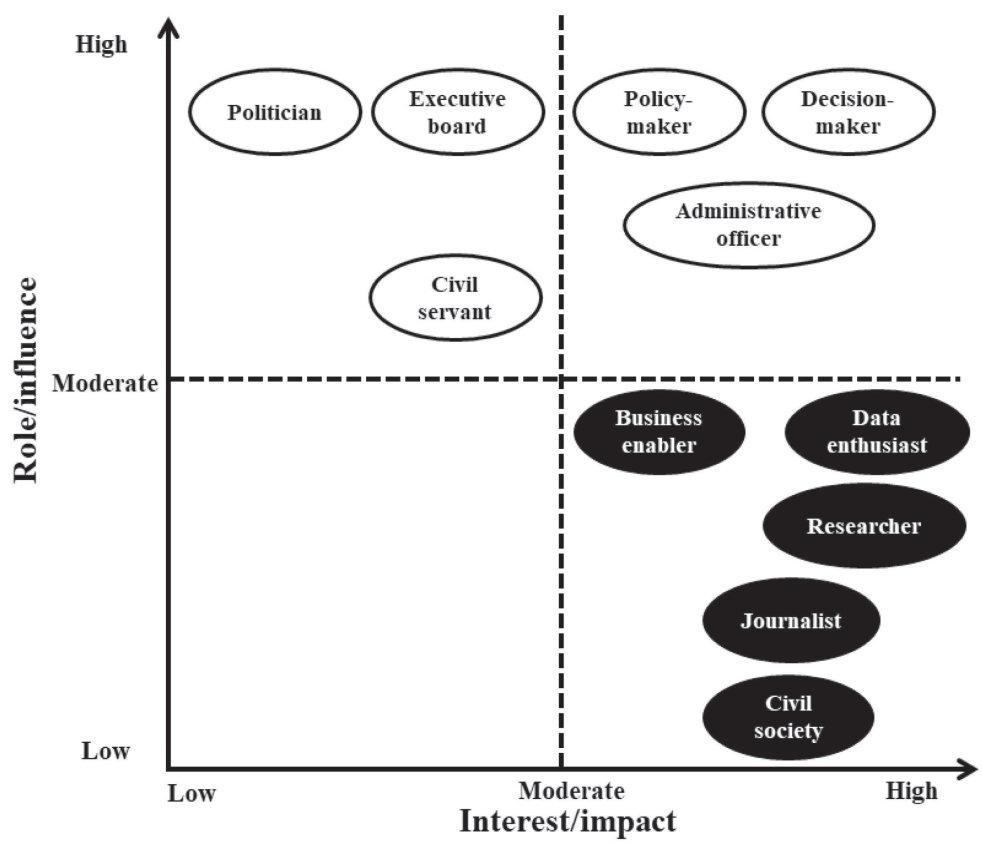

Primary stakeholders (data publishers)

Secondary stakeholders (data users)

Fig. 1. Role and interest grid of stakeholders (Based on the framework from [4])

\subsection{Analyzing the Decision-Making Process}

In the domain of OGD, not all data publishers like executive boards, decision-makers, and administrative officers behave rationally. The difference between high-level and lowlevel capabilities in decision-making can create a perception-cognition gap [18]. For some decision-makers, using a formal method in the decision-making process is possible to implement, while others are not able to use such a method. Besides, the decisionmakers cannot have access to all the required information and relevant resources to make the best decisions $[15,19]$. Apart from incomplete information, their perspectives are bounded by cognitive limits and thus making it difficult to process appropriately [14].

From the two theories of the muddling through, we classify stakeholders operate in the root or branch domain. Data publishers are classified in the root domain. The stakeholders who are part of the regulators and decision-makers, they are dominantly following rational thinking and rigor to achieve the predetermined organization's objectives. While data users and other potential data enablers are classified in the branch domain, they might use small and irregular steps and iterate unsatisfactory results to find the best decision alternatives. They may feel reluctant to use rational thinking because of the limited resources they have. Therefore, the stakeholders in this group do not 
require such a theoretical approach. They tend to employ comparison techniques and their expertise to adjust personal and organizational objectives. Moreover, there is a standard decision-making process that criteria are not well-defined. Also, the importance of decision-making is different per organization. In contrast, some have procedures and processes in place and have even tool support; most of them leave it up to the civil servants involved in the process to open the data. These civil servants might even not be aware of the need for opening data, have limited knowledge about opening data, and did not receive any training.

There are two main points to represent the result analysis of role-interest levels. First, the primary stakeholders include politicians, decision-makers, executive board, civil servants, and administration officers; they all have their role in influencing the decision-making process. Besides, the use of the root method with procedural steps in these types of stakeholders is still dominant. Some of them are aware of the decision impacts that can cause disadvantages. While others may use their authority to refuse the decisions because of too fanatic with rationality thinking and conventional method. From the bounded rationality theory, the limitation of the cognitive competencies of stakeholders can affect the optimal decisions they made. Therefore, the decision-makers cannot access all the required information and relevant resources to which dataset should be opened.

Second, the secondary stakeholders include the data enthusiast, business enabler, researcher, journalist, and civil society the all have high interest to analyze and reuse the datasets. However, they cannot actively engage in the decision-making process. Although some of them have sufficient knowledge and rational sense in the decisionmaking complexities, these theories cannot be ultimately implemented.

\section{Findings and Recommendations}

\subsection{Why Decision-Making Processes Are Not Trivial?}

This study finds many stakeholder tensions in the decision-making process to open data. We define eight important factors to capture the challenges of data publishers to make the decision to open data. First, stakeholders have different interests and opinions about opening data. Some stakeholders are risk-averse to avoid making mistakes, whereas others promote transparency and accountability. Second, different stakeholders represent different concerns. Each stakeholder has its own goals and objectives to use and reanalyze datasets. This results in tensions between ambitions and the actual opening of data. Third, in the internal organization level, there is a tension between the value of open data and the avoiding of risks. Some stakeholders are consistent to provide new knowledge to the public, while others tend to be risk-averse. Fourth, there are no clear priorities and objectives to guide decision-making. Authorities play a huge role in determining which objectives dominate and how many resources are allocated for this and if the staff gets the necessary training and tools to open data.

Fifth, the high political ambitions are in stark contrast to the limited resources, a lack of good infrastructure and supporting methods for making decisions. Sixth, stakeholders are already overloaded and have limited time resulting in the quick release of datasets which often have limited value. The focus is on reaching the target of opening a number 
of the dataset (quantity) instead of looking at the value (quality). Seventh, for some data, there is a clear 'yes' or 'no' for opening data, but many datasets are in a grey area. The stakeholders have a lack of cognitive and limited time to an in-depth analysis of the datasets. It definitely requires training and high-skills in mathematics and computing, whereas the level of education is often low. Finally, there is a potential of conflicting interests between the data publishers about the extent to which data should be opened, and it will affect the decision-making delays.

The challenges result in tensions in the level of ambitions, the allocation of resources, acquiring technical infrastructure, and training. As a consequence, data is all too often not disclosed.

\subsection{Recommendation for Data Publishers}

Based on the several challenges found in this study, we also provide some recommendations to the government institutions to make better engagement in the decision-making process in opening data. First, establish a committee to make clear authorization to open data. The committee can provide the detailed roles of the stakeholders and prioritize the allocation of scarce resources. Second, establish a decision-making committee composition including ethics, politician, and external organizations to gain positive feedback about their concern, interest, and possible risk-averse of opening data. Third, create a knowledge-based repository that can be shared among stakeholders to make evidencebased decisions. This repository can avoid duplication of the making of mistakes and foster learning from each other best practices. Fourth, analyze the stakeholder decisionmaking process and address the stakeholder tensions. Finally, create an incentive or reward to make more motivation for the data publisher to open their data. This intensive should guide all stakeholders towards pursuing the same direction.

\section{Conclusion}

In the case, we found many tensions between stakeholders, which result in opening fewer data. The ambitious objectives of transparency, accountability, and participation were in sharp contrast to the resources allocated to open data and the providing of training and infrastructure for supporting deciding to open data. This cause of the different stakeholders has other concerns, e.g., avoiding any risks of opening data and allocate scarce resources to issues that have priority.

The decision process was still dominated by the risk-averse culture, in doubt the process was halted, and not data was opened. Some policy guidelines were used for opening data, but no rational trade-off was often made, relevant expertise was lacking, and stakeholders took hardly time for making informed decisions. The science of muddling through used in this paper helped to determine which stakeholders dominantly following rational thinking and which types of stakeholder favorably using irregular decision steps.

From the case study, we found that the data publishers, like politicians, decisionmakers, executive board, civil servants, and administration officers; they all have dominantly influenced the decision-making process. The use of root method with decomposed sequential steps can make several of these data publisher stakeholders aware of the 
potential disadvantages of decision impacts. While others might use their veto power or intervention to refuse the decisions because of overly dogmatist with rationality methods. Besides, we classified the data users in the branch method, whereby they might use irregular steps and iterate unsatisfactory decisions to find the best results. Therefore, they do not need such theoretical strategies, and tend to employ comparison techniques based on their expertise to calibrate personal and organizational expectations.

From the bounded rationality theory, the limitation of the cognitive competencies of the open data stakeholders can influence the optimal decisions they made. Decisionmakers cannot access all the required information and relevant resources to which dataset should be opened. In order to tackle the cognitive gaps between the stakeholders, in this study, we recommend the data publishers to establish a knowledge-based repository that can help to make evidence-based decisions, and to encourage learning from other stakeholder's best practices. Also, we recommend to align the stakeholder interests by providing the right incentives and avoiding to be overly ambitious and stay focus on opening as many datasets as possible. Besides, we suggest to ensure the datasets offering value are disclosed to the public.

\section{References}

1. Jetzek, T.: Managing complexity across multiple dimensions of liquid open data. Gov. Inf. Q. 33(1), 89-104 (2016)

2. Luthfi, A., Janssen, M., Crompvoets, J.: Framework for analyzing how governments open their data: institution, technology, and process aspects influencing decision-making. In: EGOVCeDEM-ePart 2018. Donau-Universität Krems, Edition Donau-Universität Krems, Austria (2018)

3. Luthfi, A., Janssen, M., Crompvoets, J.: A causal explanatory model of Bayesian-belief networks for analysing the risks of opening data. In: Shishkov, B. (ed.) BMSD 2018. LNBIP, vol. 319, pp. 289-297. Springer, Cham (2018). https://doi.org/10.1007/978-3-319-94214-8_20

4. Bryson, J.M.: What to do when stakeholders matter. Public Manag. Rev. 6(1), 21-53 (2004)

5. Ackermann, F., Eden, C.: Strategic management of stakeholders: theory and practices. Long Range Plan. 44, 179-196 (2011)

6. Gonzales-Zapata, F., Heeks, R.: The multiple meanings of open government data: understanding different stakeholders and their perspective. Gov. Inf. Q. 32, 441-452 (2015)

7. Mitchell, R.K., Agle, B.R., Wood, D.J.: Toward a theory of stakeholder identification and salience: defining the principle of who and what really counts. Acad. Manag. Rev. 22(4), 853-886 (2012)

8. Savage, G.T., et al.: Strategies for assessing and managing organizational stakeholders. Acad. Manag. Perspect. 5(2), 61-75 (1991)

9. Lindblom, C.E.: The science of "muddling through". Public Adm. Rev. 19(2), 79-88 (1959)

10. Kopecka, J., Santema, S., Buijs, J.: Designerly ways of muddling through. J. Bus. Res. 65(6), 729-739 (2012)

11. Johnston, W., Low, B., Wilson, T.: Scientific muddling: decision making through a Lindblomian lens. J. Bus. Res. 65(6), 717-719 (2012)

12. Scherizer, R.: The internationalization process of SMEs: a muddling-through process. J. Bus. Res. 65(6), 745-751 (2012)

13. Kuk, G., et al.: Exploring the implementation blind spots: selective decoupling of freedom of information. In: Thirty Eight International Conference on Information Systems. Association for Information Systems, Seoul (2017) 
A. Luthfi et al.

14. Gigerenzer, G., Selten, R.: Bounded Rationality - The Adaptive Toolbox. MIT Press, Cambridge (2002)

15. Simon, H.A.: Theories of bounded rationality. Decis. Organ. 1(1), 161-176 (1972)

16. Zuiderwijk, A., Janssen, M., David, C.: Innovation with open data: essential elements of open data ecosystems. Inf. Polity 19(2-3), 17-33 (2014)

17. Janssen, M., Charalabidis, Y., Zuiderwijk, A.: Benefits, adoption barriers and myths of open data and open government. Inf. Syst. Manag. 29(4), 258-268 (2012)

18. Hoffmann, S.: Bridging the gap between perception and cognition: an overview. In: Performance Psychology, pp. 135-149 (2016)

19. Wang, L., Jiang, Y.: Escape dynamics based on bounded rationality. Phys. A: Stat. Mechan. Appl. 531, 121777 (2019) 